\title{
Acquisition and retention of conditioned aversions to context and taste in laboratory mice
}

\author{
Sezen Kislal ${ }^{1,2}$ • David A. Blizard ${ }^{1}$
}

Published online: 9 November 2017

(C) Psychonomic Society, Inc. 2017

\begin{abstract}
We compared the rate of acquisition and strength of retention of conditioned context aversion (CCA) with conditioned taste aversion (CTA) using pigmented, genetically heterogeneous mice (derived from Large and Small strains). Extending previous findings, in Experiment 1, mice accustomed to drinking from large glass bottles in the colony room learned to avoid graduated tubes after a single conditioning trial when drinking from these novel tubes was paired with injections of $\mathrm{LiCl}$. The results also showed that CCA could be developed even when there was a 30-minute delay between conditioned stimulus and unconditioned stimulus. Retention of the aversion lasted for 4 weeks in both Immediate and Delay groups. Studies of conditioned saccharin aversion were conducted in Experiment 2. CTA acquisition was very similar to that observed in CCA and duration of aversion retention was similar in the CCA and CTA Delay groups, although at least 2 weeks longer in the Immediate group. Thus, CCA acquisition and retention characteristics are closer to those seen for CTA than has previously been reported. In Experiment 3, we examined whether albino mice (which are known to have weaker visual abilities compared to pigmented mice) would develop CCA comparable to those of pigmented mice. The development of conditioned aversion and its duration of retention was similar in albinos and pigmented mice. Nonspecific aversion emerged as an important contributor to strength of aversion during retention trials in both CCA and
\end{abstract}

Sezen Kislal

sezenk@stanford.edu

1 Department of Biobehavioral Health, Pennsylvania State University, State College, USA

2 School of Medicine, Neurosurgery, Stanford University, Palo Alto, CA 94304, USA
CTA paradigms with pigmented (but not albino) mice and deserves additional scrutiny in this field of inquiry.

Keywords Classical conditioning · Conditioned taste aversion $\cdot$ Conditioned context aversion

The experimental pairing of a novel tastant with radiationinduced sickness was first shown by Garcia and colleagues (Garcia, Ervin, \& Koelling, 1966; Garcia, Kimeldorf, \& Koelling, 1955) to result in strong and long-lasting aversions. Aversions were produced even when novel solutions were strongly preferred (e.g., saccharin and sucrose) and when a variety of other treatments (e.g., $\mathrm{LiCl}$, apomorphine) was used to induce sickness (Cannon, Best, Batson, \& Feldman, 1983; Foynes \& Riley, 2004; Hunt \& Amit, 1987; Mickley, Kenmuir, Yocom, Wellman, \& Biada, 2005; Nachman \& Ashe, 1973; Parker, 2003; Welzl, D’Adamo, \& Lipp, 2001). A single pairing of a novel tastant with illness (Bernstein \& Webster, 1980; Garcia et al., 1966; Garcia et al., 1955) was found to be sufficient to produce a conditioned taste aversion (CTA). In addition, strong aversions could be demonstrated when a substantial delay was introduced between a conditioned stimulus (CS) and an unconditioned stimulus (UCS; Garcia et al., 1966; Revusky \& Garcia, 1970; Smith \& Roll, 1967).

Like CTA, aversions to contextual stimuli paired with illness have been well studied (Archer, Sjödén, Nilsson, \& Carter, 1979 1980; Boakes, Westbrook, Elliott, \& Swinbourne, 1997; Revusky \& Parker, 1976; Rodriguez, Lopez, Symonds, \& Hall; 2000) and reviewed (Stockhorst, Enck, \& Klosterhalfen, 2007; Stockhorst, Steingrueber, Enck, \& Klosterhalfen, 2006). More specifically, studies have paired toxicosis with substantive alterations in housing environments (a variety of changes in visual, chemesthetic, acoustic, or tactile stimuli) to develop conditioned context aversion 
(CCA; Boakes et al., 1997; Revusky \& Parker, 1976; Rodriguez et al., 2000). Most of these experimental studies have been conducted using laboratory rats (Boakes et al., 1997; Revusky \& Parker, 1976; Rodriguez et al., 2000).

Our recent studies using genetically heterogeneous mice have shown that pairing illness with drinking from a novel water container in the home cage also results in CCA (Kislal \& Blizard, 2016). Mice were able to form strong aversions after a single pairing of the $\mathrm{CS}$ with lithium chloride $(\mathrm{LiCl})$ when the maintenance container was a plastic bottle and the CS was a glass bottle (Kislal \& Blizard, 2016, Experiment 1), or, when the maintenance container was a glass bottle and the CS, a graduated tube (Kislal \& Blizard, 2016, Experiment 2). However, when the maintenance and CS tubes only differed in the brightness of a piece of tape, two trials were required to form an equally strong conditioned aversion (Kislal \& Blizard, 2016, Experiments 2 and 3). In addition, in this latter experimental configuration, CCA was shown to be formed when a 30-min delay was interpolated between CS and UCS. However, retention, in this case, was short-lived compared to that typically found in CTA paradigms, consisting of 2 weeks when the CS-UCS pairing was immediate and 1 week when there was a 30-minute CS-UCS delay (Kislal \& Blizard, 2016, Experiment 3).

Although emphasis has been placed on the acquisition of CTA after a single aversive conditioning trial and the longlasting retention of taste aversions, there have been few attempts to compare these features of CTA and CCA within a comparable experimental framework. The present experiments were therefore conducted to formally compare the duration of retention of both $\mathrm{CCA}$ and $\mathrm{CTA}$ in mice and to explore the effect of CS-UCS delay in both paradigms using mice drawn from the same stock and employing similar procedures. A different genetically heterogeneous stock of mice was used than that used in our earlier experiments, which should provide a broader basis for generalization of these phenomena in mice. Based on previous literature on CTA and our own experiments on CCA, we predicted that the mice would show a more rapid acquisition and longer duration of retention for CTA compared to CCA.

Differences between maintenance and novel drinking containers in our previous experiments were primarily visual in nature (at least by design), and attempts were made to minimize variations in other sensory modalities (touch, olfaction) by using similar sipper tubes and rubber stoppers. Relevant to the visual emphasis of our experimental protocol, another aim of our experiments was to compare albino and pigmented mice in their ability to develop CCA. A review of recent literature suggests that most (but not all) albino mice have weaker visual abilities than pigmented mice do (Wong \& Brown, 2006). For instance, it has been shown that pigmented mice with no known visual impairment have a visual acuity between 0.38 and $0.5 \mathrm{c} / \mathrm{deg}$, whereas some albino strains have a visual acuity below $0.17 \mathrm{c} / \mathrm{deg}$ (Gianfranceschi, Fiorentini, \& Maffei, 1999; Wong \& Brown, 2006). Thus, pigmented mice are generally about 60 to 80 times weaker in visual acuity compared to humans (the visual acuity of humans is about 30 c/deg; Prusky, Harker, Douglas, \& Whishaw, 2002), while albinos are approximately 180 times weaker (with noted exceptions such as albino AKR/J mice; Wong \& Brown, 2006). We predicted that albino mice would be slower to acquire CCA than pigmented mice would, and retain conditioned aversions for a shorter length of time.

In general, our experimental design placed emphasis on distinguishing between the contribution of sensitization and specific factors to the strength of aversions following conditioning trials. The results supported the relevance of this concern to both CCA and CTA experimental designs.

\section{Experiment 1}

As noted, our previous studies showed that mice maintained on pint-sized glass bottles developed strong aversion for up to 13 days to graduated tubes when ingestion of water from the tubes was paired with $\mathrm{LiCl}$ (Kislal \& Blizard, 2016, Experiment 2). The present experiment was carried out to provide more evidence that the same CS-UCS pairing results in aversion when using a different genetically heterogeneous cross. We also planned to examine the duration of retention and the effect of a CS-UCS delay during acquisition.

\section{Method}

The following methods and procedures are common to all three experiments and have been approved by the IACUC (Institutional Animal Care and Use Committee) of The Pennsylvania State University.

\section{Colony room}

A 12/12-hr light/dark cycle (lights on 0500-1700 hrs) was maintained with temperature at $72^{\circ} \mathrm{F}+/-2$. There was no natural light in the room. Mice were housed in plastic cages (height: $12 \mathrm{~cm}$, width: $18 \mathrm{~cm}$, length: $29.5 \mathrm{~cm}$ ) with wire tops for the whole experiment. Rodent Lab Diet 5001 (PMI International; Brentwood, MO) and tap water were available ad libitum during the experiments, except when animals were water restricted, as described below.

\section{Experimental design}

Subjects The subjects were 48 pigmented male genetically heterogeneous mice (mean age 93 days, range: 87-100 days) from an advanced intercross (AI) of Large (LG) and Small (SM) strains. There were 18 different litters, and litter 
membership was evenly distributed across the four experimental groups (see Table 1). Body weights were recorded at the beginning and end of the experiments.

Training to drink Before the experiment, mice were routinely maintained in groups using pint-size translucent plastic bottles with blue plastic lids and metal pinhole spouts. As shown in Fig. 1 (adaptation), they were individually caged and then habituated to drinking water from pint-size regular glass bottles (GB) with rubber stoppers and stainless steel spouts with ball bearings for 7 days. Mice were then trained to drink water promptly from the same glass bottles (drink training) in the light phase of the circadian cycle by depriving them of water at 5 p.m., and giving them access to water for 30 minutes on two occasions at $9.00 \mathrm{a} . \mathrm{m}$. and $12 \mathrm{p} . \mathrm{m}$. the following day and then were allowed to drink from 2 p.m. until 5 p.m. (the beginning of the dark phase). This procedure was repeated on 3 consecutive days (see Fig. 1).

Conditioning procedures During the conditioning trials, tap water in graduated tubes (with the same ball-bearing spouts as the maintenance bottle) with pieces of dark tape attached to the tubes near their spouts (GT) was presented to waterdeprived mice for 15 minutes in their home cage. Spout lengths were the same for both kinds of bottles, and they were inserted a similar distance into the home cage. Using the same kind of spouts for both tubes was intended to avoid haptic features or proprioceptive stimuli from becoming part of the contextual variation. Experimental groups were injected with lithium chloride $(\mathrm{LiCl})(0.15 \mathrm{M}, 0.3 \mathrm{~mL} / 10 \mathrm{~g}$ body weight $)$ immediately or 30 minutes after the graduated tubes had been removed from the cages: GB-GT ${ }^{\text {LiCl/Immed }}$ and GB-GT ${ }^{\mathrm{LiCl}}$ Delay (see Table 1). The control groups were injected with sodium chloride $(\mathrm{NaCl})$ in the same manner as the $\mathrm{LiCl}$ groups (same concentration and dose as $\mathrm{LiCl}$ ): $\mathrm{GB}-\mathrm{GT}^{\mathrm{NaCl} / \mathrm{Im} m e d}$ and GB-GT ${ }^{\mathrm{NaCl} / \mathrm{Delay}}$ (see Table 1). Their regular glass bottles were returned to the home cage 20 minutes after the CS tubes were removed from cages. After the last conditioning trial, the mice were allowed a recovery period of 6 days where they were provided with food and water ad libitum (see Fig.1).

Retention tests The water deprivation restarted 16 hours before the retention test (CCA 3+6 days; see Fig. 1). Retention tests (42 minutes in duration) were administered over 2 days at weekly intervals after recovery (e.g., CCA 3+7 days, CCA 3+ 14 days). To provide an opportunity to assess the potential contribution of sensitization (i.e., the contribution of nonspecific factors to intake during retention), each mouse was given access to water from a graduated tube with dark tape on the initial day and, on the following day, the maintenance bottle, or vice versa (half of the animals in each experimental group were presented with the maintenance bottle first and CS tube second, the other half, the reverse order). Intake from the graduated tube provided an estimate of total aversion (conditioned aversion and sensitization), the maintenance bottle, nonspecific aversion (sensitization) and the difference between the two, conditioned aversion.

\section{Data analyses}

Statistical analyses were performed using SPSS (Version 20, IBM). The primary tool was analysis of variance (ANOVA). Statistical significances were reported as $<.05,<.01,<.001$. Partial eta squared $\left(\mathrm{n}_{\mathrm{p}}{ }^{2}\right)$ was reported as a measure of effect size for omnibus analyses of variance, and it was routinely included in the reporting of results. In addition, a $t$ test was used to determine statistical significance for follow-up tests using Bonferroni protection. One-tail or two-tail tests were used as appropriate.

\section{Conditioning analyses}

Analyses of variance of water intakes during conditioning involved two between-subjects factors, Groups (Experimental vs. Control) and CS-UCS Interval (Immediate vs. Delay), as well as a within-subjects measure (Trials).

\section{Retention analyses}

Analyses of variance of intakes involved three betweensubjects factors, groups (control vs. experimental), CS-UCS interval (immediate vs. delay), and CS Order (CS presented first or second within each week), as well as two withinsubjects measures that were trials (6) and tubes (CS vs. regular).

Table 1 Experimental groups and the bottle configurations for Experiment 1

\begin{tabular}{llllll}
\hline Groups & Regular tubes & CS & Injection & Abbreviation & Number of mice \\
\hline Control & Glass bottle (GB) & Graduated tubes (GT) & NaCl (Immediate) & GB-GT NaCl/Immed & $N=12$ \\
& Glass bottle (GB) & Graduated tubes (GT) & NaCl (Delay) & GB-GT NaCl/Delay & $N=12$ \\
Experimental & Glass bottle (GB) & Graduated tubes (GT) & LiCl (Immediate) & GB-GT LiC//mmed & $N=12$ \\
& Glass bottle (GB) & Graduated tubes (GT) & LiCl (Delay) & GB-GT ${ }^{\text {LiCl/Delay }} \quad N=12$ \\
\hline
\end{tabular}




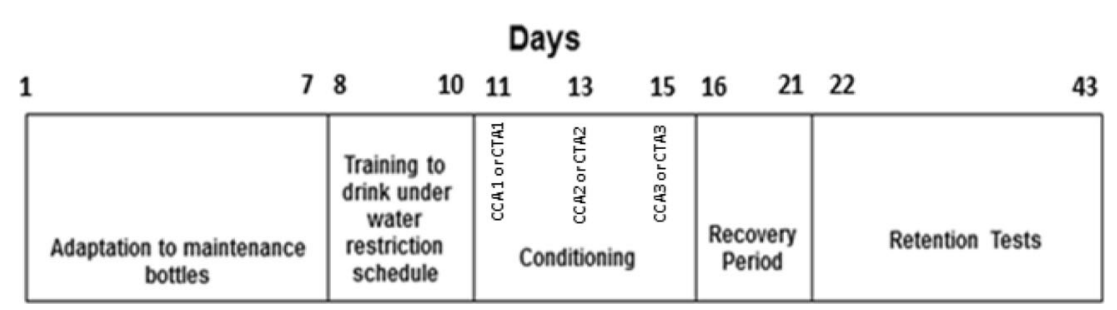

Fig. 1 General procedure used in experiments. Experiment consisted of five phases: adaptation, drink training, CCA/CTA (conditioned context aversion/conditioned taste aversion), recovery, and retention. Top row:

\section{Results}

\section{Conditioning}

The water intakes during conditioning are shown in Fig. 2. Experimental groups had significantly lower intakes than the control groups: groups, $F(1,44)=83.32, p<.001, \mathrm{n}_{\mathrm{p}}{ }^{2}=0.65$, and water intake levels decreased across trials, $F(2,88)=$ 27.76, $p<.001, \mathrm{n}_{\mathrm{p}}{ }^{2}=0.39$. In addition, a significant Group $\times$ Trial interaction, $F(2,88)=47.72, p<.001, \mathrm{n}_{\mathrm{p}}{ }^{2}=0.52$, and a Trial $\times$ Groups $\times$ CS-UCS Interval interaction, $F(2,88)=$ $4.09, p<.05, \mathrm{n}_{\mathrm{p}}{ }^{2}=0.09$, were observed. The interactions were assessed by performing a one-way ANOVA on each trial. As expected, on CCA 1, there was no significant difference among the groups, $F(1,44)=0.23, p=.63, \mathrm{n}_{\mathrm{p}}{ }^{2}=0.01$, and no interaction for the Groups $\times$ CS-UCS Interval, $F(1,44)=$ $1.20, p=.28, \mathrm{n}_{\mathrm{p}}{ }^{2}=0.03$, reflecting the fact that the groups had been maintained under similar conditions before conditioning. However, on both CCA 2 and CCA 3, water intake was lower in the experimental groups compared to control: CCA 2, F(1, $44)=106.91, p<.001, \mathrm{n}_{\mathrm{p}}{ }^{2}=0.71$, and CCA $3, F(1,44)=$ $258.85, p<.001, \mathrm{n}_{\mathrm{p}}{ }^{2}=0.86$, and there was interaction for the Groups $\times$ CS-UCS Interval only on CCA 3 ; CCA 2, F(1, 44)
Please note that the number of days devoted to retention phase varied by experiment

$$
\begin{aligned}
& =2.26, p=0.14, \mathrm{n}_{\mathrm{p}}{ }^{2}=0.04 ; \text { and CCA } 3, F(1,44)=4.27, p< \\
& .05, \mathrm{n}_{\mathrm{p}}{ }^{2}=0.09 \text {. }
\end{aligned}
$$

The control, immediate, and delay groups were also separately examined using repeated measures ANOVA. Withingroup analyses of variance showed that water intake increased across trials in the control group: $F(2,44)=5, p<.05, \mathrm{n}_{\mathrm{p}}{ }^{2}=$ 0.19 , only in the immediate group animals, Trials $\times$ CS-UCS interaction, $F(2,44)=8.06, p<.01, \mathrm{n}_{\mathrm{p}}{ }^{2}=0.27$ (see Fig. 2), while water intake decreased in each of the experimental groups: trials, CCA 1 to CCA $2, F(1,22)=61.93, p<.001$, $\mathrm{n}_{\mathrm{p}}{ }^{2}=0.74 ;$ CCA 2 to CCA $3, F(1,22)=10.60, p<.01, \mathrm{n}_{\mathrm{p}}{ }^{2}=$ 0.33 ; CCA 1 to CCA 3, $F(2,44)=68.92, p<.001, \mathrm{n}_{\mathrm{p}}{ }^{2}=0.76$ (see Fig. 2), but there was no Trials $\times \mathrm{CS}-\mathrm{UCS}$ interaction, CCA 1 to CCA 2, $F(1,22)=0.22, p=.65, \mathrm{n}_{\mathrm{p}}{ }^{2}=0.01 ; \mathrm{CCA} 2$ to $\mathrm{CCA} 3, F(1,22)=2.50, p=.13, \mathrm{n}_{\mathrm{p}}{ }^{2}=0.10 ; \mathrm{CCA} 1$ to CCA $3, F(2,44)=0.28, p=.76, \mathrm{n}_{\mathrm{p}}^{2}=0.01$ (see Fig. 2).

\section{Retention}

There was no significant difference in water intake associated with presenting the CS tubes first or second each week, so data were combined across the two presentations.

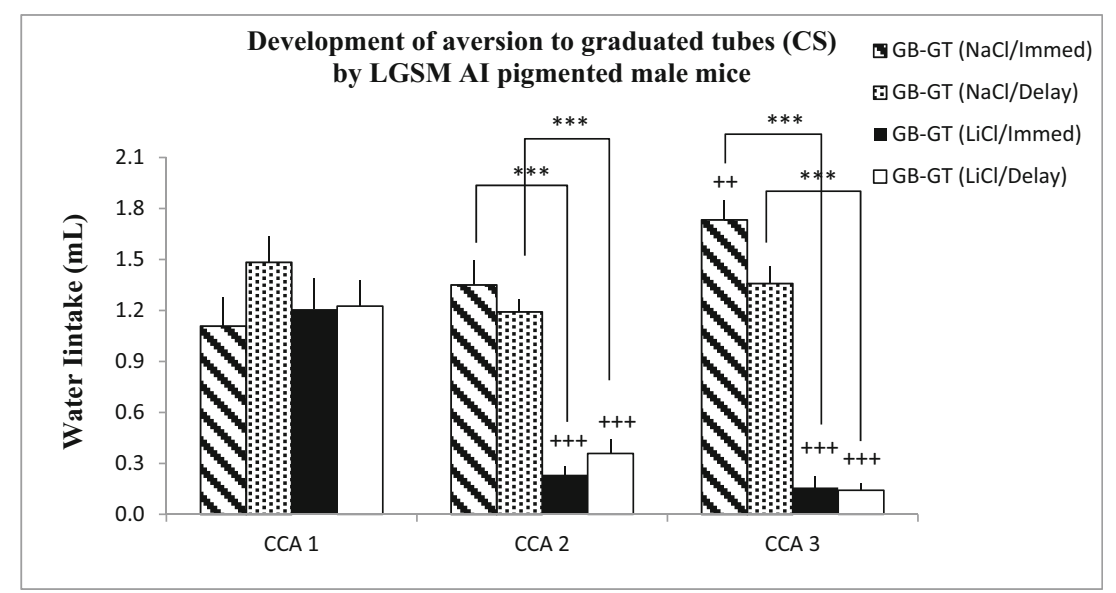

Fig. 2 Water intake during conditioning trials $(M \pm S E)$.Pigmented LGSM (large and small strains) AI (advanced intercross ) male mice maintained on glass bottles (GB) were exposed to three conditioning trials when they drank from graduated tubes with dark-colored tape (GT) paired with either injections of $\mathrm{LiCl}$ (lithium chloride) or $\mathrm{NaCl}$ (sodium chloride) immediately or 30 minutes later (delay). The aversion was clearly observed on both CCA 2 and CCA 3 for both immediate and delay experimental groups. $* * * p<.001$ compared to control group intakes, $++p<.01 ;+++p<.001$ compared to intake of same group on CCA 1. See Table 1 for an explanation of abbreviations 
Experimental groups had significantly lower water intakes than the control groups: groups, $F(1,44)=33.06, p<.001, \mathrm{n}_{\mathrm{p}}^{2}$ $=0.43$, and water intake levels increased across trials, $F(5$, $220)=13.22, p<.001, \mathrm{n}_{\mathrm{p}}{ }^{2}=0.23$. In addition, analyses showed that, compared to control groups, experimental groups drank less from the CS tubes than from maintenance tubes, Tubes $\times$ Groups interaction, $F(1,220)=30.92, p<$ $.001, \mathrm{n}_{\mathrm{p}}^{2}=0.41$. A statistically significant Groups $\times$ Tubes $\times$ Trials interaction, $F(5,220)=7.19, p<.001, \mathrm{n}_{\mathrm{p}}^{2}=0.14$, was followed up by conducting analyses for each tube.

The group differences in water intake from the CS tubes are shown in Fig. 3a and maintenance bottles in Fig. 3b. CS tube intake analysis showed that experimental groups had significantly lower water intakes than the control groups: groups, $F(1,44)=54.78, p<.001, \mathrm{n}_{\mathrm{p}}^{2}=0.56$. In addition, water intake levels increased across trials in experimental groups compared to control groups, Trials $\times$ Groups interaction, $F(5,220)=$ $12.32, p<.001, \mathrm{n}_{\mathrm{p}}^{2}=0.22$. The main effect of groups, $F(1$, 44) $=9.81, p<.01, \mathrm{n}_{\mathrm{p}}{ }^{2}=0.18$, in the maintenance tube intake analysis also showed that experimental group mice drank less than controls, albeit at a lower level of significance. However, there was no Trials $\times$ Groups interaction, $F(5,220)=0.55, p=$ $0.74, \mathrm{n}_{\mathrm{p}}{ }^{2}=0.01$, in this analysis and Fig. $3 \mathrm{~b}$ shows little trend in intakes across trials.

\section{Suppression ratios}

Suppression indices were calculated to take into account baseline water intake in control mice on each trial. Each animal's intake was subtracted from the appropriate control group mean for that trial, and the difference score was divided by mean control group intake, subtracted from 1 and expressed as
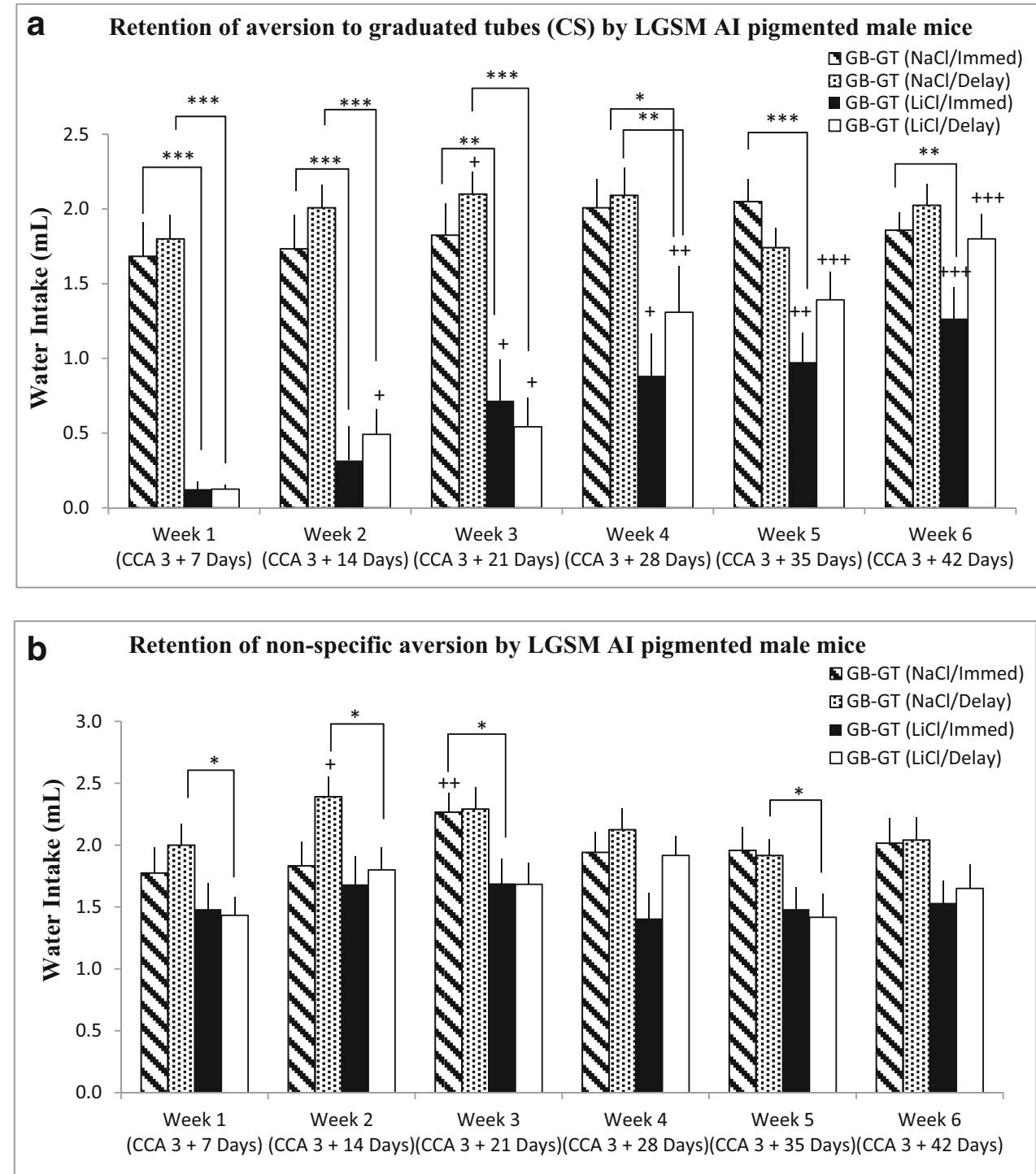

Fig. 3 Water intake during retention trials $(M \pm S E)$. Both total a (CS tube; graduated tubes with dark tape) and $\mathbf{b}$ nonspecific (maintenance tube; glass bottle) retention were tested at weekly intervals after CCA 3.
$* p<.05 ; * * p<.01 ; * * * p<.001$ compared to control group intakes, $+p<$ $.05 ;++p<.01 ;+++p<.001$ compared to intake of same group on Week 1. See Table 1 for an explanation of abbreviations 
a \%. ((1 - [intake of the individual animal] / [mean intake of the control group] $) \times 100$ ). For example, $0 \%$ suppression indicates the same intake as control, $100 \%$ suppression indicates $0 \mathrm{~mL}$ intake (Nowlis, Frank, \& Pfaffmann, 1980). Analyses of suppression of retention showed that experimental group mice showed greater overall suppression to CS tubes than to glass bottles (maintenance tubes): tubes, $F(1,110)=133.284, p<$ $.001, \mathrm{n}_{\mathrm{p}}{ }^{2}=0.86$; a decrease in suppression to CS tubes for experimental groups across trials, Tubes $\times$ Trials, $F(5,110)=$ $15.42, p<.001, \mathrm{n}_{\mathrm{p}}{ }^{2}=0.41$; no significant differences in suppression between the immediate and delay groups: CS-UCS interval, $F(1,22)=0.37, p=.55, \mathrm{n}_{\mathrm{p}}{ }^{2}=0.02$, and no difference between immediate and delay groups in the rate of disappearance of the specific conditioned aversion, Trials $\times$ Tubes $\times$ CS-UCS Interval; $F(5,110)=0.56, p=.73, \mathrm{n}_{\mathrm{p}}{ }^{2}=0.03$, the suppression levels decreased across trials for both experimental groups, $F(5,110)=11.88, p<.001, \mathrm{n}_{\mathrm{p}}{ }^{2}=0.35$. Specific suppression can be inferred when total suppression is greater than nonspecific, and greater total versus nonspecific suppression was found in Weeks 1-4 for both immediate and delay groups (total vs. nonspecific suppression; Weeks 1-4, paired $t$ test, $p$ s ranging from $<.01$ to .01$)$. Consistent with extinction, there was no significant difference between total and nonspecific suppression within either of the conditioned groups after Week 4 (total vs. nonspecific suppression; Weeks 5-6, paired $t$ test, $p$ s ranging from .06 to .94).

\section{Discussion}

Our studies with B6D2 AI mice (Kislal \& Blizard, 2016, Experiment 2) showed that pairing illness with minor environmental changes (switching from glass bottle to graduated tubes) resulted in strong aversion. The results of Experiment 1 on pigmented LGSM AI mice confirm this finding. Mice, drinking in the colony from glass bottles, learned to avoid graduated tubes after a single conditioning trial when drinking from these was paired with injections of lithium chloride. In addition, the result shows that GB-GT ${ }^{\mathrm{LiCl} / \mathrm{Immed}}$ and GB-GT ${ }^{\mathrm{LiCl} / \text { Delay }}$ groups retain the aversion for 4 weeks. The duration of retention was not tested for this combination of stimuli (GB vs. GT) in our earlier experiment, but the length of retention shown here is longer than was found when maintenance and CS tubes only differed in the brightness of a piece of tape attached to the tubes (Kislal \& Blizard, 2016, Experiment 3). In our earlier experiment (Kislal \& Blizard, 2016, Experiment 3), we found substantial nonspecific aversion when maintenance and CS tubes differed by the brightness of a piece of tape but little evidence when the difference was more substantial (switching from glass bottle to graduated tubes; see Fig. 4). Thus, the present experiment extends evidence of nonspecific aversion in providing evidence of modest but statistically significant nonspecific aversion when mice drank from their maintenance tubes. Thus, the total aversion shown by experimental mice when switching from a glass bottle to a graduated tube reflects for the most part specific aversion to the CS but includes a minor component attributable to sensitization.

\section{Experiment 2}

The results of Experiment 1 with a different stock of mice than previously used (Kislal \& Blizard, 2016) show that pairing illness with small changes in the cage environment can result in specific aversion that lasts approximately 4 weeks. In the present case, both the immediate and delay experimental groups retained the aversion to a similar degree. The aim of the following experiment was to compare the duration of retention in Experiment 1 for CCA with that for CTA using a

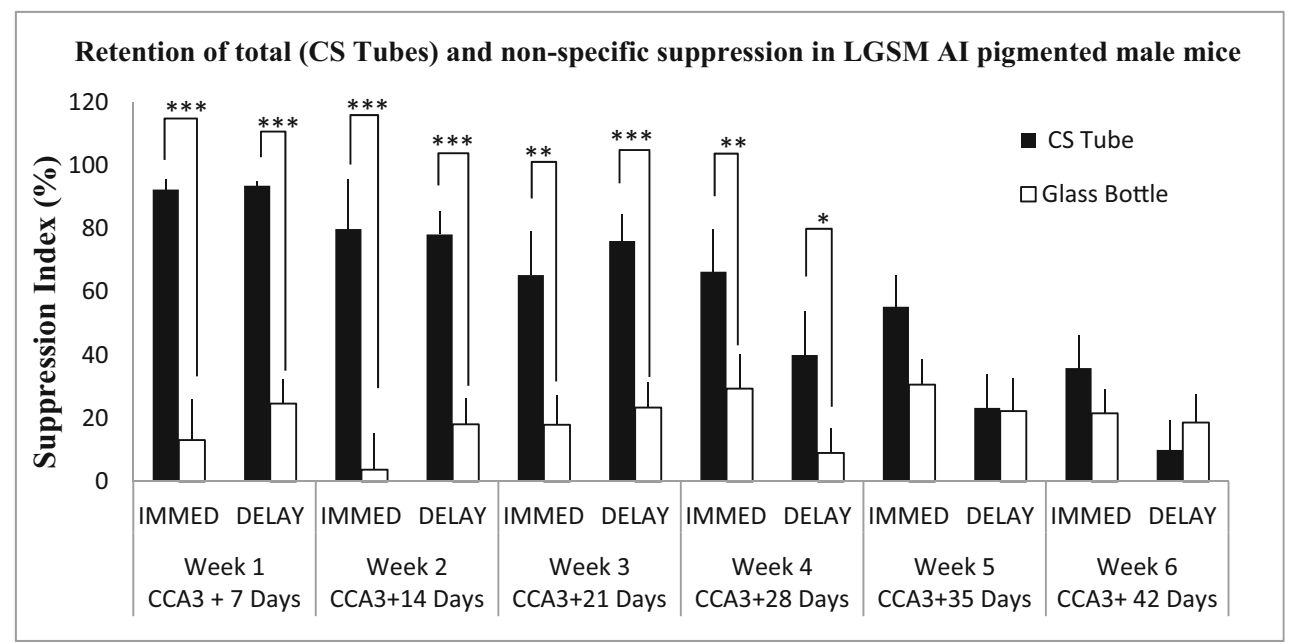

Fig. 4 Percentage suppression during retention trials $(M \pm S E)$. Both total and nonspecific retention were tested at weekly intervals after CCA 3. There was specific suppression (total greater than nonspecific suppression) through Week 4 in both the immediate and delay experimental groups. * $p<.05 ; * * p<.01 ; * * *<.001$ compared to suppression of same group 
similar experimental paradigm. Aversions were established to sodium saccharin (CS) by pairing its ingestion with an injection of $\mathrm{LiCl}$ during the conditioning phase delivered immediately or after a 30-minute delay. Before performing these experiments, we predicted that the mice would show a longer duration of retention for CTA compared to CCA.

\section{Experimental design}

Subjects The subjects were 44 pigmented male genetically heterogeneous mice (mean age 125 days, range: 120-130 days) from an advanced intercross (AI) of Large (LG) and Small (SM) strains. There were 10 different litters, and litter membership was evenly distributed across the four experimental groups (see Table 2).

\section{Method}

Maintenance conditions were similar to those described in the previous experiment. Before the experiment, the mice were routinely maintained on pint-size translucent plastic bottles with blue plastic lids and metal spouts. The mice were then habituated to drinking water from $25-\mathrm{mL}$ graduated tubes, rubber stoppers, and stainless steel spouts with ball bearings for 7 days. Drink training proceeded as previously described (see Fig. 1).

\section{Conditioning procedures}

During the conditioning trials, sodium saccharin $(5 \mathrm{mM})$ (Sacc) was presented in graduated tubes to water-deprived mice for 15 minutes in their home cage. The two experimental groups were injected with lithium chloride $(\mathrm{LiCl})(0.15 \mathrm{M}, 0.3$ $\mathrm{mL} / 10 \mathrm{~g}$ body weight) immediately or 30 minutes after the graduated tubes were removed from their cages: (Sacc ${ }^{\mathrm{LiCl} /}$ Immed and Sacc ${ }^{\text {LiCl/Delay }}$ ). The control groups were injected with sodium chloride $(\mathrm{NaCl})$ in the same manner as the $\mathrm{LiCl}$ groups (the same concentration and dose used for $\mathrm{LiCl}$ ): Sacc $\mathrm{NaCl} / \mathrm{Immed}$ and Sacc ${ }^{\mathrm{NaCl} / \text { Delay }}$ (see Table 2).

After the last conditioning trial, the mice were allowed a recovery period of 6 days. During this period, the animals had ad libitum access to water in their maintenance tubes.

\section{Retention tests}

Retention tests were administered over two days in each week after the recovery period (e.g., CTA $3+7$ days, CTA $3+14$ days) as described for Experiment 1.

If a mouse had access to sodium saccharin (CS) on the initial day, on the following day, water was presented, or vice versa. Both sodium saccharin and water was presented in their maintenance tubes (graduated tubes) during the retention test. This provided us with an opportunity to assess the total (saccharin intake from graduated tubes) and nonspecific suppression (water intake from graduated tubes).

\section{Data analyses}

Conditioning analyses Analyses of variance of saccharin intakes during conditioning involved two between-subjects factors, groups (experimental vs. control) and CS-UCS interval (immediate vs. delay), as well as a within-subjects measure (trials).

Retention analyses Analyses of variance of intakes involved three between-subjects factors, groups (control vs. experimental), CS-UCS interval (immediate vs. delay), and CS order (CS presented first or second within each week), as well as two within-subjects measures that were trials (6) and solution (saccharin vs. water).

\section{Results}

\section{Conditioning}

The saccharin intakes during conditioning are shown in Fig. 5. Experimental groups had significantly lower intakes than the control groups: groups, $F(1,40)=42.14, p<.001, \mathrm{n}_{\mathrm{p}}^{2}=0.51$, and saccharin intake levels decreased across trials, $F(2,80)=$ 7.93, $p<.001, \mathrm{n}_{\mathrm{p}}{ }^{2}=0.17$. In addition, a significant Group $\times$ Trial interaction, $F(2,80)=37.52, p<.001, \mathrm{n}_{\mathrm{p}}{ }^{2}=0.48$, and a Trial $\times$ Groups $\times$ CS-UCS Interval interaction, $F(2,80)=$ $4.33, p<.05, \mathrm{n}_{\mathrm{p}}{ }^{2}=0.10$, were observed. The interactions were assessed by performing a one-way ANOVA on each trial. As expected, on CTA 1, there was no significant difference among the groups, $F(1,40)=0.02, p=0.88, \mathrm{n}_{\mathrm{p}}{ }^{2}=0.001$. However, on both CTA 2 and CTA 3, saccharin intake was lower in the experimental groups compared to controls: CTA

Table 2 Experimental groups and the taste configurations for Experiment 2

\begin{tabular}{|c|c|c|c|c|c|}
\hline Groups & Regular tubes & CS & Injection & Abbreviation & Number of mice \\
\hline \multirow[t]{2}{*}{ Control } & Graduated tubes & Graduated tubes with sodium saccharin (Sacc) & $\mathrm{NaCl}$ (Immediate) & $\mathrm{Sacc}^{\mathrm{NaC} / \mathrm{Immed}}$ & $N=10$ \\
\hline & Graduated tubes & Graduated tubes with sodium saccharin (Sacc) & $\mathrm{NaCl}$ (Delay) & Sacc ${ }^{\mathrm{NaCl} / \text { Delay }}$ & $N=12$ \\
\hline \multirow[t]{2}{*}{ Experimental } & Graduated tubes & Graduated tubes with sodium saccharin (Sacc) & LiCl (Immediate) & Sacc ${ }^{\mathrm{LiCl} / \mathrm{Immed}}$ & $N=10$ \\
\hline & Graduated tubes & Graduated tubes with sodium saccharin (Sacc) & $\mathrm{LiCl}$ (Delay) & Sacc LiC/Delay & $N=12$ \\
\hline
\end{tabular}




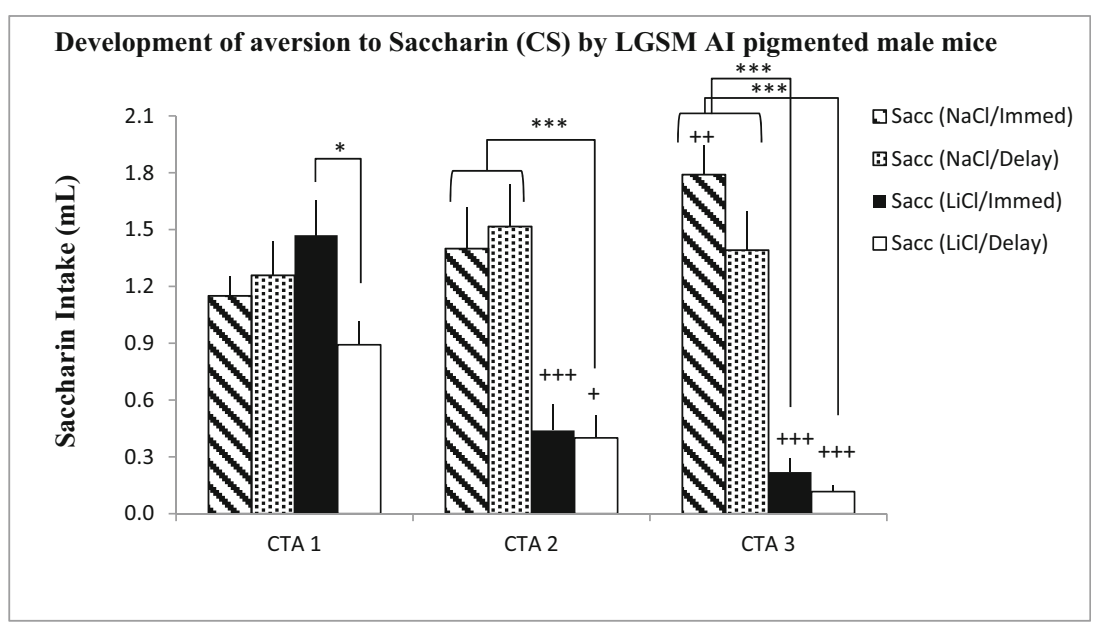

Fig. 5 Saccharin intake during conditioning trials $(M \pm S E)$. Pigmented LGSM AI (large and small strains advanced intercross) male mice maintained on water in graduated tubes were exposed to three conditioning trials when they drank sodium saccharin in their maintenance tubes paired with either injections of LiCl (lithium chloride) or $\mathrm{NaCl}$ (sodium chloride) immediately or 30 minutes later

2, $F(1,40)=32.22, p<.001, \mathrm{n}_{\mathrm{p}}{ }^{2}=0.45$, and CTA $3, F(1,40)$ $=104.73, p<.001, \mathrm{n}_{\mathrm{p}}{ }^{2}=0.72$, and there was no interaction for the Groups $\times$ CS-UCS Interval, CTA2, $F(1,40)=0.04, p=$ $.67, \mathrm{n}_{\mathrm{p}}{ }^{2}=0.01$, and CTA3, $F(1,40)=1.13, p=.30, \mathrm{n}_{\mathrm{p}}{ }^{2}=0.03$.

Each group was also separately examined via repeatedmeasures ANOVAs. Within-group analyses of variance showed that although saccharin intake increased across trials in the control group, $F(2,40)=4.79, p<.05, \mathrm{n}_{\mathrm{p}}{ }^{2}=0.19$, there was no significant difference between the response of the immediate and delay control groups from CTA 1 to CTA 3, Trials $\times$ CS-UCS interval, $F(2,40)=2.69, p=0.08, \mathrm{n}_{\mathrm{p}}{ }^{2}=$ 0.12 (see Fig. 5). In the analysis of the experimental groups, there was a main effect for trials, CTA1 to CTA2, $F(1,20)=$ $38.21, p<.001, \mathrm{n}_{\mathrm{p}}{ }^{2}=0.66$; CTA2 to CTA $3, F(1,20)=9.36, p$ $<.01, \mathrm{n}_{\mathrm{p}}{ }^{2}=0.32$; CTA1 to CTA3, $F(2,40)=47.52, p<.001$, $\mathrm{n}_{\mathrm{p}}{ }^{2}=0.70$ (see Fig. 5), reflecting the fact that saccharin intake levels decreased across trials. In addition, a Trial $\times$ CS-UCS Interval interaction, $F(2,40)=3.70, p<.05, \mathrm{n}_{\mathrm{p}}{ }^{2}=0.16$ (see Fig. 5), reflected the fact that the immediate group had higher saccharin intake levels on CTA 1 compared to the delay group, CTA $1, t(20)=2.67, p<.05$, but the groups did not differ during CTA 2 and CTA 3: CTA $2, t(20)=0.22, p=0.83$; CTA3, $t(20)=1.36, p=0.19$.

\section{Retention}

There was no significant difference in fluid intake associated with presenting the saccharin solution first or second each week, so data were combined across the two presentations.

Experimental groups had significantly lower fluid intakes than the control groups: groups, $F(1,40)=45.98, p<.001, \mathrm{n}_{\mathrm{p}}{ }^{2}$ $=0.54$, and fluid intake levels increased across trials, $F(5,200)$ (delay). The aversion was clearly observed on both CTA 2 and CTA 3 for both the immediate and delay experimental groups. $* p<.05$; *** $p<$ .001 compared to control group intakes; $+p<.05 ;++p<.01 ;+++p<.001$ compared to intake of same group on CTA 1. See Table 2 for an explanation of abbreviations

$=12.69, p<.001, \mathrm{n}_{\mathrm{p}}{ }^{2}=0.24$. In addition, compared to control groups, experimental groups drank less saccharin than water, Solution $\times$ Groups interaction, $F(1,200)=35.30, p<.001, \mathrm{n}_{\mathrm{p}}{ }^{2}$ $=0.47$. A statistically significant Groups $\times$ Solution $\times$ Trials interaction, $F(5,200)=2.62, p<.05, \mathrm{n}_{\mathrm{p}}{ }^{2}=0.06$, was followed up by conducting analyses for each solution.

The group differences in solution intake are shown in Figs. 6a (sodium saccharin intake) and $6 \mathrm{~b}$ (water intake). Saccharin intake analysis showed that experimental groups had significantly lower saccharin intakes than the control groups, ranging from an almost complete suppression of intake in Week 1 (mean of immediate and delay control groups $=1.86$ vs. 0.16 in combined experimental groups) to approximately $25 \%$ in the combined groups in Week 6, groups, $F(1,40)=62.26, p<.001, \mathrm{n}_{\mathrm{p}}{ }^{2}=$ 0.61 (mean intake of combined controls $=2.1$ vs. combined experimentals, 1.5). Reflecting extinction, saccharin intake levels increased across trials in experimental groups compared to occasional, nonsystematic changes in the control groups, Trials $\times$ Groups interaction, $F(5,200)=9.09, p<.001, \mathrm{n}_{\mathrm{p}}{ }^{2}=0.19$ (see Fig. 6a). In the analysis of water intakes, the main effect of groups, $F(1,40)=10.13, p<.01, \mathrm{n}_{\mathrm{p}}{ }^{2}=0.20$, also showed that experimental group mice drank less overall than controls, although the effect was modest and restricted to three of the first four trials. In addition, there was a Trials $\times$ Groups interaction, $F(5,200)=2.58, p<.05, \mathrm{n}_{\mathrm{p}}{ }^{2}=0.06$, reflecting sporadic increases in water intake levels on different trials in the two groups (see Fig. 6b).

\section{Suppression ratios}

In order to compare the duration of retention across weeks in immediate and delay experimental groups, suppression ratios 

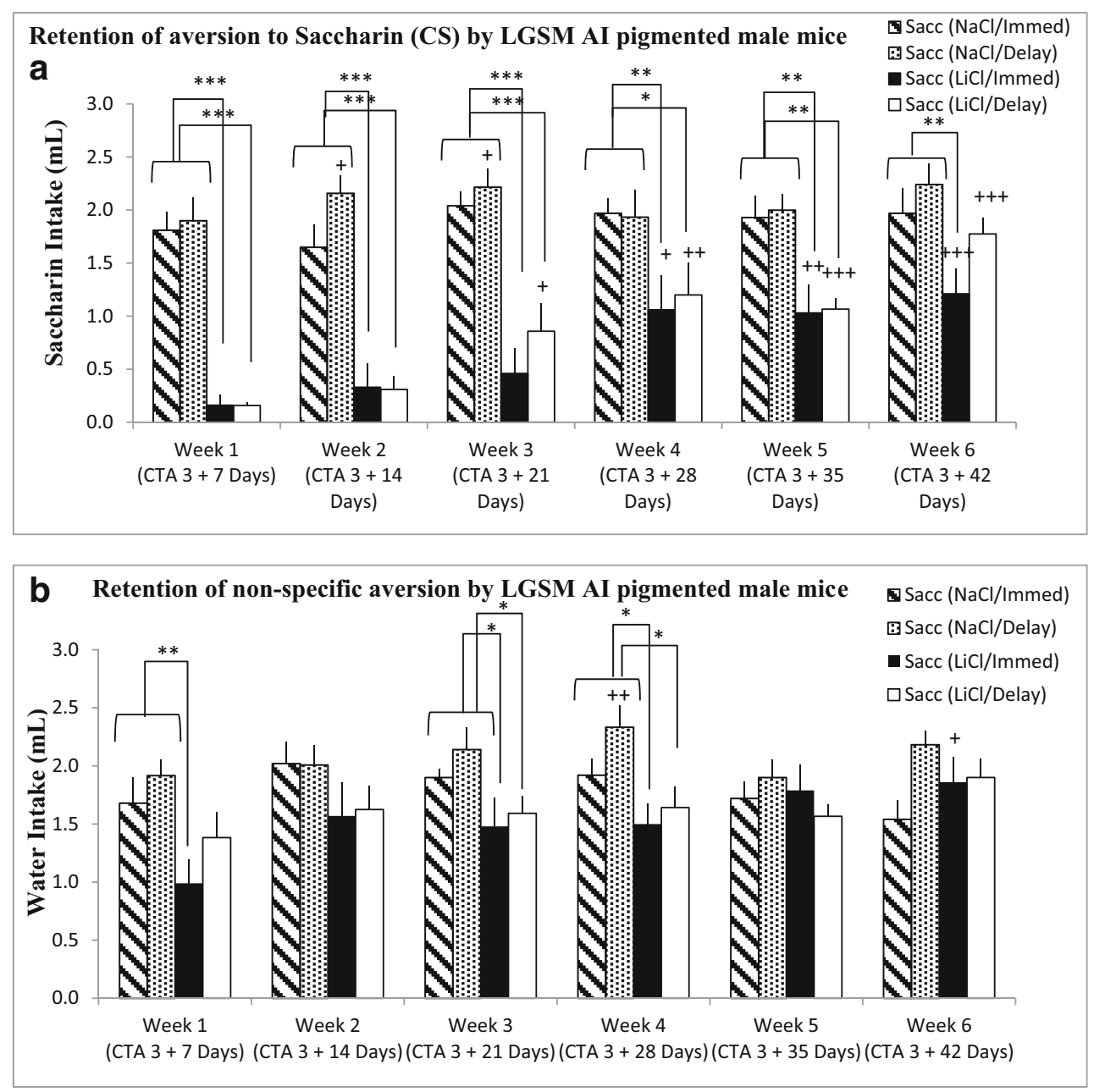

Fig. 6 Fluid intake during retention trials $(M \pm S E)$. Both total a (CS; sodium saccharin) and $\mathbf{b}$ nonspecific (water) retention were tested at weekly intervals after CTA $3 . * p<.05 ; * * p<.01 ; * * p<.001$ compared to control group intakes; there was no significant difference between

were calculated as described in Experiment 1. Analyses of suppression of all retention results showed a larger suppression by experimental mice to saccharin than to water: solution, $F(1,100)=39.57, p<.001, \mathrm{n}_{\mathrm{p}}{ }^{2}=0.66 ;$ no overall differences in suppression between the immediate and delay groups, CSUCS interval, $F(1,20)=0.02, p=0.88, \mathrm{n}_{\mathrm{p}}{ }^{2}=0.001$. There was a main effect for trials, $F(5,100)=16.39, p<.001, \mathrm{n}_{\mathrm{p}}^{2}=$ 0.45 , reflecting the fact that suppression levels decreased across the trials and a significant CS-UCS Interval $\times$ Solution $\times$ Trials interaction, $F(5,100)=2.64, p<.05, \mathrm{n}_{\mathrm{p}}{ }^{2}=$ 0.12 , indicating a difference between the immediate and delay groups in the gradual disappearance of the specific conditioned aversion. Total suppression was greater than nonspecific suppression through Week 6 in the immediate group (total vs. nonspecific; Weeks $1-6$, paired $t$ test, $p$ s ranging from $<.05$ to .01). For the delay group, the total versus nonspecific suppression only differed significantly during Weeks 1-3 (total vs. nonspecific; Weeks $1-3$, paired $t$ test, $p$ s ranging from $<.01$ intakes of immediate and delay control mice, so these data were combined to assess the effects of conditioning within each trial, $+p<.05 ;++p$ $<.01 ;+++p<.001$ compared to intake of same group on Week 1 . See Table 2 for an explanation of abbreviations

to .001) but not thereafter (total vs. nonspecific suppression; Weeks 4-6, paired $t$ test, $p$ s ranging from .15 to .54) Fig. 7.

\section{Discussion}

Based on extensive research (Bernstein \& Webster, 1980; Garcia et al., 1966; Garcia et al., 1955; Revusky \& Garcia, 1970; Smith \& Roll, 1967), a single pairing of a novel taste with illness results in strong conditioned aversion to the novel taste. There are many examples of similar results in inbred mice (e.g., Horowitz \& Whitney; 1975; Nachman, Larue, \& Le Magnen; 1971), so it is not surprising that we were able to corroborate these findings in genetically heterogeneous mice: strong conditioned taste aversion appeared after a single conditioning trial even when a 30-minute delay was introduced between the presentation of the CS and the UCS. 


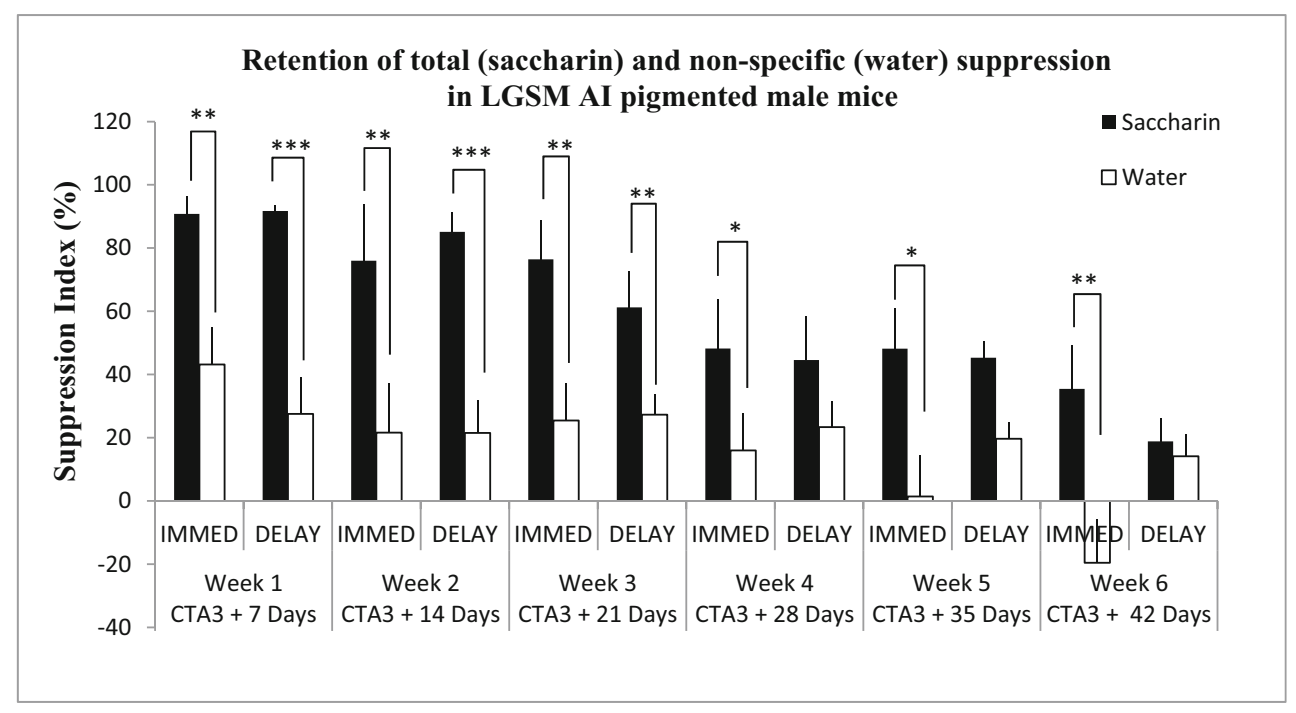

Fig. 7 Percentage suppression during retention trials $(M \pm S E)$. Both total and nonspecific retention were tested at weekly intervals after CTA 3. There was specific suppression (total greater than nonspecific

Comparing rates of CCA acquisition, the results of Experiment 1 demonstrate that mice accustomed to drinking from glass bottles in their home cages learned to avoid graduated tubes after a single conditioning trial when drinking from these tubes was paired with injections of lithium chloride. Thus, CCA and CTA were both acquired after a single aversion conditioning trial (see Fig. 5 and Fig. 2).

CTA was retained longer (through Week 6) compared to CCA (through Week 4) in immediate group mice. On the other hand, in delay mice, retention lasted for about the same duration (3 or 4 weeks) in CTA and CCA studies.

The present experiment also provided important evidence of slight nonspecific aversion when the mice, conditioned to avoid saccharin, drank water. Thus, like CCA, CTA reflects both a specific and a small nonspecific component. Comparing nonspecific suppression in CCA and CTA studies, conditioned aversion decreased across trials (from Weeks 1-6) in the study of taste, whereas it remained stable during this same period in the CCA study.

\section{Experiment 3}

In the current experiment, we compared the response of albino mice to the previous results obtained with pigmented animals. A review of recent literature suggests that most albino mice have weaker visual abilities than pigmented mice do (Wong \& Brown, 2006). The aim of our experiments, then, was to examine whether albino mice would develop CCA comparable to those of pigmented mice. In this study, the magnitude of CCA was examined by performing similar alterations to those described in Experiment 1 (switching from glass bottles to graduated tubes). We again compared retention of conditioned suppression) through Week 6 in the immediate group and Week 3 in the delay group. $* p<.05 ; * * p<.01 ; * * * p<.001$ compared to suppression of same group

aversions by injecting the mice either immediately or after a 30-minute delay between the presentation of CS and the UCS.

We predicted that albino LGSM AI mice would show slower rates of conditioning, lower magnitudes of aversion, and faster extinction compared to pigmented mice.

\section{Experimental design}

\section{Subjects}

The subjects were 36 albino male genetically heterogeneous mice (mean age 70 days, range: $67-80$ days) from an advanced intercross (AI) of Large (LG) and Small (SM) strains (from the same genetic stock as pigmented mice). There were 12 different litters, and litter membership was evenly distributed across the four experimental groups. Consistent with our previous experiments, there were no statistical differences between immediate and delay control groups in the current experiment, and their data were combined for statistical analyses.

\section{Method}

Maintenance conditions were similar to those described in the previous experiments. Before the experiment, the mice were routinely maintained using pint-size translucent plastic bottles with blue plastic lids and metal pinhole spouts. The mice were then habituated to drinking water from pint-size regular glass bottles (GB) with rubber stoppers and stainless steel spouts with ball bearings for 7 days (see Fig. 1 and Table 3). Drink training proceeded as previously described. 
Table 3 Experimental groups and the bottle configurations for Experiment 3

\begin{tabular}{llllll}
\hline Groups & Regular tubes & CS & Injection & Abbreviation & Number of mice \\
\hline Control & Glass bottle (GB) & Graduated tubes (GT) & NaCl (Immediate) & GB-GT NaC//mmed & $N=6$ \\
& Glass bottle (GB) & Graduated tubes (GT) & NaCl (Delay) & GB-GT ${ }^{\text {NaCl/Delay }}$ & $N=6$ \\
Experimental & Glass bottle (GB) & Graduated tubes (GT) & LiCl (Immediate) & GB-GT LiC//mmed & $N=12$ \\
& Glass bottle (GB) & Graduated tubes (GT) & LiCl (Delay) & GB-GT & $N=12$ \\
\hline
\end{tabular}

\section{Conditioning procedures}

Conditioning proceeded as previously described in Experiment 1. Two experimental groups (12 mice per group) were injected with lithium chloride $(\mathrm{LiCl})(0.15 \mathrm{M}, 0.3 \mathrm{~mL} /$ $10 \mathrm{~g}$ body weight) immediately or 30 minutes after the graduated tubes had been removed from mice's cages: GB-GT ${ }^{\mathrm{LiCl}}$ Immed and GB-GT ${ }^{\text {LiC/Delay }}$ (see Table 3). The control groups were injected with sodium chloride $(\mathrm{NaCl})$ in the same manner as the $\mathrm{LiCl}$ groups (same concentration and dose as $\mathrm{LiCl}$ ): GB-GT ${ }^{\mathrm{NaCl} / \mathrm{Immed}}$ and GB-GT ${ }^{\mathrm{NaCl} / \text { Delay }}$ (see Table 3). Their regular glass bottles were returned to the home cage $20 \mathrm{mi}-$ nutes after the CS tubes were removed from cages. After the last conditioning trial, the mice were allowed a recovery period of 6 days. During this period, the animals had ad libitum access to their regular bottles (see Fig. 1).

\section{Retention tests}

The water deprivation restarted 16 hours before the retention test (CCA $3+6$ days). Retention tests (42 minutes in duration) were administered over two days at weekly intervals after recovery (e.g., CCA $3+7$ days, CCA $3+14$ days). If a mouse had access to water from a graduated tube with dark tape (the $\mathrm{CS}$ ) on the initial day, on the following day, a glass bottle (the maintenance tube) was presented, or vice versa. This provided us with an opportunity to assess the total (graduated tube with dark-colored tape) and nonspecific (glass bottle) aversion.

\section{Data analyses}

Conditioning analyses Analyses of variance of water intakes during conditioning involved two between-subjects factors, groups (experimental vs. control) and CS-UCS interval (immediate vs. delay), as well as a within-subjects measure (trials).

Retention analyses Analyses of variance of intakes involved three between-subjects factors, groups (control vs. experimental), CS-UCS interval (immediate vs. delay), and CS order (CS presented first or second within each week), as well as two within-subjects measures that were trials (6) and tubes (CS vs. regular).

\section{Results}

\section{Conditioning}

The water intakes during conditioning are shown in Fig. 8 . Experimental groups had significantly lower intakes than the

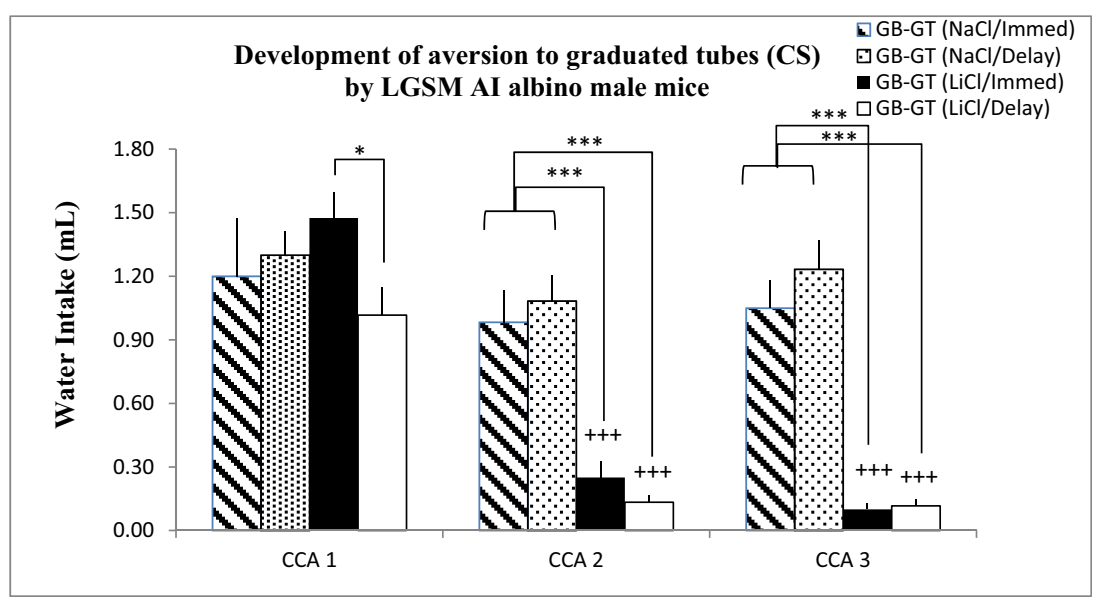

Fig. 8 Water intake during conditioning trials $(M \pm S E)$. Albino LGSM AI (large and small strains advanced intercross) male mice maintained on glass bottles (GB) were exposed to three conditioning trials when they drank from graduated tubes with dark-colored tape (GT) paired with either injections of $\mathrm{LiCl}$ (lithium chloride) or $\mathrm{NaCl}$ (sodium chloride) immediately or 30 minutes later (delay). The aversion was clearly observed on both CCA 2 and CCA 3 for both immediate and delay experimental groups. $* p<.05 ; * * * p<.001$ compared to control group intakes, $+++p<.001$ compared to intake of same group on CCA 1 . See Table 3 for an explanation of abbreviations 
control groups: groups, $F(1,32)=49.86, p<.001, \mathrm{n}_{\mathrm{p}}^{2}=0.61$, and water intake levels decreased across trials, $F(2,64)=$ 67.01, $p<.001, \mathrm{n}_{\mathrm{p}}{ }^{2}=0.68$. In addition, a significant Group $\times$ Trial interaction, $F(2,64)=38.02, p<.001, \mathrm{n}_{\mathrm{p}}{ }^{2}=0.54$, was observed. The interactions were assessed by performing a one-way ANOVA on each trial. There was no significant difference between intakes of immediate and delay control mice, so their data were combined to assess the effects of conditioning for each trial. As expected, on CCA 1, there was no significant difference among the groups, $F(1,32)=0.001, p=$ $.98, \mathrm{n}_{\mathrm{p}}{ }^{2}=0.00$. However, on both CCA 2 and CCA 3, water intake was lower in the experimental groups compared to controls: CCA 2, $F(1,32)=88.32, p<.001, \mathrm{n}_{\mathrm{p}}{ }^{2}=0.73$, and CCA 3, $F(1,32)=209.46, p<.001, \mathrm{n}_{\mathrm{p}}^{2}=0.87$.

Each group was also separately examined via repeatedmeasures ANOVAs. In the analysis of the control groups, there was no main effect for trials, $F(2,20)=2.25, p=.13$, $\mathrm{n}_{\mathrm{p}}^{2}=0.18$, reflecting the stable level of water consumption across the trials, but there was no Trials $\times$ CS-UCS interaction, $F(2,20)=0.11, p=.89, \mathrm{n}_{\mathrm{p}}{ }^{2}=0.01$. In the analysis of the experimental groups, there was a main effect for trials: trials CCA 1 to CCA 2, $F(1,23)=145.37, p<.001, \mathrm{n}_{\mathrm{p}}{ }^{2}=0.86$; CCA 2 to CCA $3, F(1,23)=4.33, p<.05, \mathrm{n}_{\mathrm{p}}{ }^{2}=0.16$; CCA 1 to CCA $3, F(2,44)=152.56, p<.001, \mathrm{n}_{\mathrm{p}}{ }^{2}=0.87$, reflecting the fact that water intake levels decreased across the trials. In addition, a Trial $\times$ CS-UCS Interval interaction, $F(2,44)=$ $5.69, p<.01, \mathrm{n}_{\mathrm{p}}{ }^{2}=0.21$ (see Fig. 8) reflected that the immediate group had higher water intake levels from the CS tube during CCA 1 compared to the delay group: CCA $1, t(22)=$ $2.60, p<.05$; however, the groups did not differ during CCA 2 and CCA 3: CCA 2, $t(22)=1.4, p=.18, \operatorname{CCA~3;~} t(22)=$ $-0.41, p=.69$.

\section{Retention}

There was no significant difference in water intake associated with presenting the CS tubes first or second each week, so data were combined across the two presentations.

Experimental groups had significantly lower water intakes than the control groups: groups, $F(1,32)=11.37, p<.01, \mathrm{n}_{\mathrm{p}}{ }^{2}$ $=0.26$, and water intake levels increased across trials, $F(5$, $160)=14.10, p<.001, \mathrm{n}_{\mathrm{p}}^{2}=0.31$. In addition, analyses showed that, compared to control groups, experimental groups drank less from the CS tubes than from maintenance tubes: Tubes $\times$ Groups interaction, $F(1,160)=30.39, p<$ $.001, \mathrm{n}_{\mathrm{p}}{ }^{2}=0.49$. A statistically significant Groups $\times$ Tubes $\times$ Trials interaction, $F(5,160)=6.32, p<.001, \mathrm{n}_{\mathrm{p}}{ }^{2}=0.17$, was followed up by conducting analyses for each tube.

The group differences in water intake from the CS tubes are shown in Fig. 9a and maintenance bottles in Fig. 9b. CS tube intake analysis showed that experimental groups had significantly lower water intakes than the control groups: groups, $F(1,32)=28.62, p<.001, \mathrm{n}_{\mathrm{p}}{ }^{2}=$
0.47. In addition, water intake levels increased across trials in experimental groups compared to control groups, Trials $\times$ Groups interaction, $F(5,160)=10.99, p<.001$, $\mathrm{n}_{\mathrm{p}}{ }^{2}=0.26$. Maintenance tube intake analysis showed that there was no main effect of groups, $F(1,32)=0.40, p=$ $.53, \mathrm{n}_{\mathrm{p}}^{2}=0.01$, and Trials $\times$ Groups interaction, $F(5,160)$ $=0.54, p=0.75, \mathrm{n}_{\mathrm{p}}{ }^{2}=0.02$, reflecting the stable level of water consumption across the retention trials in both experimental and control groups.

Analyses of intake of all retention results showed that there were no overall differences in aversion between the immediate and delay experimental groups: CS-UCS interval, $F(1,22)=$ $3.42, p=.07, \mathrm{n}_{\mathrm{p}}{ }^{2}=0.14$, and no Trials $\times$ Tubes $\times$ CS-UCS Interval interaction, $F(5,110)=0.32, p=.9, \mathrm{n}_{\mathrm{p}}{ }^{2}=0.01$, indicating there were no significant difference in the gradual disappearance of the specific conditioned aversion. However, there was a main effect for trials, $F(5,110)=21.11, p<$ $.001, \mathrm{n}_{\mathrm{p}}{ }^{2}=0.49$, reflecting the fact that aversion levels decreased across the trials.

Since nonspecific aversion was not observed in albino mice, the duration of retention in the immediate and delay experimental groups was calculated by comparing the intake from the CS tubes using an independent-samples $t$ test (unpaired) between the control groups and each conditioned group. As noted, there was no significant difference between the intake of immediate and delay control mice; therefore, these data were combined to assess the effects of retention within each trial. There was a significantly lower intake from CS tubes in Weeks 1-4 for the immediate group (controls vs. GB-GT ${ }^{\mathrm{LiCl} / \mathrm{Immed}}$; Weeks $1-4$, independent-samples $t$ test, $p$ s ranging from $<.01$ to .001 ; see Fig. 9a), and in Weeks 1-3 for the delay group (controls vs. GB-GT LiCl/Delay; Weeks $1-3$, independentsamples $t$ test, $p$ s ranging from <.01 to .001 ; see Fig. 9a). Consistent with extinction, there was not a significantly lower intake from CS tubes in Weeks 5-6 for the immediate group (controls vs. GB-GT LiCl/Immed; Weeks 5-6, independent-samples $t$ test, $p$ s ranging from .09 to .96 ), and Weeks 4-6 for the delay group (controls vs. GB-GT LiCl/Delay; Weeks 4-6, independent-samples $t$ test, $p$ s ranging from .06 to .55 ).

\section{Discussion}

There was no support for the prediction that albino mice would develop weaker CCA acquisition and retention than pigmented mice.

Like pigmented mice, albino mice developed strong suppression to the CS tubes after only a single conditioning trial. In addition, there were no significant differences between the immediate and delay experimental groups in their responses to conditioning, thus paralleling the results of Experiment 1. 


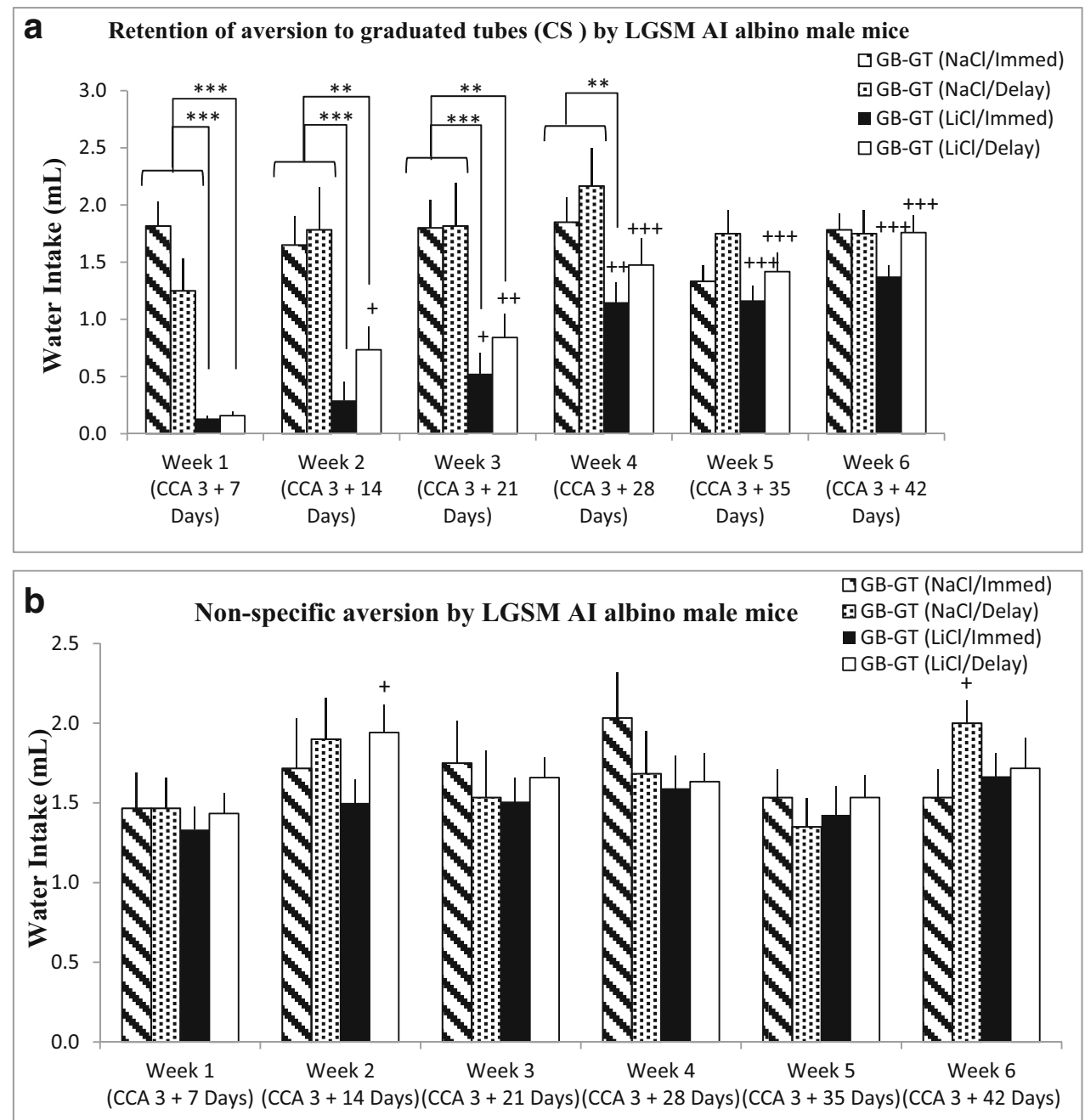

Fig. 9 Water intake during retention trials $(M \pm S E)$. Both total a (CS tube; graduated tubes with dark-tape) and $\mathbf{b}$ nonspecific (maintenance tube; glass bottle) retention were tested at weekly intervals after CCA 3 . $* * p<.01 ; * * * p<.001$ compared to control group intakes; there was no significant difference between intakes of immediate and delay control mice, so these data were combined to assess the effects of conditioning within each trial, $+p<.05 ;++p<.01 ;+++p<.001$ compared to intake of same group on Week 1. See Table 3 for an explanation of abbreviations
The duration of retention was similar in both pigmented and albino mice. When there was a 30-minute delay between the presentation of the CS and the UCS, conditioned context aversion was retained longer (through Week 4) in pigmented mice than in albino mice (through Week 3). On the other hand, in immediate experimental groups, there was no difference between albino and pigmented mice: retention lasted for 4 weeks.

Surprisingly, the present experiment showed a lack of nonspecific aversion by albino mice. Thus, the total aversion shown by albino mice reflects only the specific aversion to the CS tubes without any sensitization effect. Even though albino mice did not show any aversion to their maintenance tubes during the retention tests, they showed a similar degree of aversion response to the CS tubes as pigmented mice. These results point to a difference in the specificity of learning in albino and pigmented mice.

\section{General discussion}

Our recent studies with outbred mice from a cross of C57BL/ $6 \mathrm{~J}$ and DBA/2J strains (Kislal \& Blizard, 2016) showed that inducing illness (resulting from $\mathrm{LiCl}$ injections) following ingestion of water from a novel container resulted in strong inhibition of drinking following subsequent presentations. The results from the current experiments with mice derived from a different outbred cross (derived from LG and SM strains) extended these findings and added important information about the duration of retention of conditioned context aversions.

As can be seen in Table 4, groups of mice conditioned to avoid the novel water container acquired the aversion in a single trial and, as judged by the difference between total aversion and nonspecific aversion in the case of the pigmented mice (Fig. 4) retained it for 4 weeks. The albino mice did not 
Table 4 Duration of CCA and CTA retention in LGSM AI mice

\begin{tabular}{llllll}
\hline & Experimental groups & Subjects & Acquisition & CS-UCS interval & Duratio of retention \\
\hline Experiment 1 & GB-GT LiCl/Immed & LGSM AI (Pigmented) & 1 Trial & Immediate & 4 weeks \\
& GB-GT LiC//Delay & LGSM AI (Pigmented) & 1 Trial & Delay & 4 weeks \\
Experiment 2 & Sacc LiCl/Immed & LGSM AI (Pigmented) & 1 Trial & Immediate & 6 weeks \\
& Sacc ${ }^{\text {LiCl/Delay }}$ & LGSM AI (Pigmented) & 1 Trial & Delay & 3 weeks \\
Experiment 3 3 & GB-GT LiCl/Immed & LGSM AI (Albino) & 1 Trial & Immediate & 4 weeks \\
& GB-GT Lic//Delay & LGSM AI (Albino) & 1 Trial & Delay & 3 weeks \\
\hline
\end{tabular}

exhibit a significant degree of nonspecific aversion, but they also retained the aversion for 3 (delay group) or 4 (immediate group) weeks.

The nonspecific suppression that was seen in Experiment 1 varied between approximately $4 \%$ and $30 \%$ and did not change systematically across trials. By contrast, specific suppression, as judged by the difference between total and nonspecific suppression, was highest on the first retention trial (total suppression, $\sim 92 \%$; nonspecific, $\sim 14 \%$ ) and decreased substantially by the fourth retention trial (total suppression, $\sim 66 \%$; nonspecific, $\sim 30 \%$ ). The lack of nonspecific suppression in albino mice was not expected. We predicted that albino mice would exhibit weaker aversion and shorter retention (due to poorer visual acuity), but there was no indication of that in our findings.

It was interesting to observe that animals conditioned to avoid saccharin also exhibited a significant degree of nonspecificity by reducing their intake of water on three of the first four retention trials, compared to controls. When this was taken into account by comparing saccharin and water suppression ratios in experimental and control groups, specific suppression in the delay group was only retained for 3 weeks. Retention trials were not continued long enough to determine the duration of retention in the Immediate group: it remained statistically significant in Week 6. Thus, under less favorable conditioning parameters (e.g., CSUCS, 30-min delay) retention by CTA mice was equivalent to CCA but under optimum conditions (e.g., CS-UCS, immediate) aversion was retained for longer than CCA.

The present findings indicating the existence of some degree of nonspecificity in both CCA and CTA paradigms emphasize the importance of taking this factor into consideration when attempting to precisely compare the strength of retention in these two different experimental paradigms. The contribution of nonspecificity to strength of conditioning has been frequently acknowledged in aversive conditioning paradigms. Often, experimenters attempt to "remove" nonspecific aversion by exposing mice to the control condition on several occasions after completion of conditioning before estimating "specific" conditioning. Our findings indicate that it is important to include estimates of the strength of nonspecificity concurrently with estimates of "specific" conditioning. Inclusion of such estimates in our study provided improved comparisons of CCA and CTA, particularly under boundary conditions when retention in CCA and CTA paradigms were equivalent. Another way of assessing the contribution of sensitization or nonspecific factors to aversion during retention tests would have been to include an additional control group injected with lithium chloride after drinking from maintenance bottles. Following this procedure in our laboratory, we have observed approximately $40 \%$ suppression of intake on the first retention trial, somewhat greater than that seen in Experiment 1 , but on the second retention trial, nonspecific suppression was negligible (Blizard, personal communication). Taken together, nonspecific factors clearly contribute to the strength of total aversion measured during retention trials and this result emphasizes the value of of our "concurrent" method of separately estimating total and nonspecific aversion retention.

Albino mice did not exhibit a significant degree of nonspecific aversion, a finding that appears inconsistent with the idea that albino mice have generally poorer visual acuity than pigmented animals (Wong \& Brown, 2006). Nevertheless, albinos' acquisition of aversion and duration of their retention was similar to that seen in pigmented mice. Perhaps visual acuity does not contribute to acquisition and retention of aversion in our experimental paradigm. Conceivably, substitution of a slim graduated tube for a regular glass bottle impacts mice by affecting the degree of illumination in the home cage, a change that might be more readily detected by albino mice whose enhanced sensitivity to increased illunination is well established (DeFries, Hegmann, \& Weir, 1966) and which is unlikely to be simply related to visual acuity.As noted earlier, the same kind of spout was used for both maintenance and CS tubes in order to minimize the contribution of variation in sense of touch or altered proprioception resulting from different body postures to the potential matrix of conditioned stimuli that might underlie conditioned aversion in this situation. Thus, while the contribution of other sensory modalities cannot be ruled out, visual stimuli seem most likely to be the predominant CS's.

Overall, the comparison between rate of acquisition and length of retention of conditioned aversions in CCA and CTA paradigms emphasizes similarities between these two types of learning rather than major differences between them. 
Sensitization also contributes to total aversion in both phenomena. These findings may be important in evaluating the significance of CCA in clinical contexts.

Acknowledgements This research was generously supported by the Ford Endowment Award from the College of Health and Human Development at The Pennsylvania State University. The authors would also like to thank Joseph Gyekis for assisting with the experiments and providing helpful feedback.

\section{References}

Archer, T., Sjödén, P. O., Nilsson, L. G., \& Carter, N. (1979). Role of exteroceptive background context in taste-aversion conditioning and extinction. Animal Learning \& Behavior, 7(1), 17-22.

Archer, T., Sjödén, P. O., Nilsson, L. G., \& Carter, N. (1980). Exteroceptive context in taste aversion conditioning and extinction: Odour, cage, and bottle stimuli. The Quarterly Journal of Experimental Osychology, 32(2), 197-214.

Bernstein, I. L., \& Webster, M. M. (1980). Learned taste aversions in humans. Physiology \& Behavior, 25(3), 363-366.

Boakes, R. A., Westbrook, R. F., Elliott, M., \& Swinbourne, A. L. (1997). Context dependency of conditioned aversions to water and sweet tastes. Journal of Experimental Psychology: Animal Behavior Processes, 23(1), 56.

Cannon, D. S., Best, M. R., Batson, J. D., \& Feldman, M. (1983). Taste familiarity and apomorphine-induced taste aversions in humans. Behaviour Research and Therapy, 21(6), 669-673.

DeFries, J. C., Hegmann, J. P., \& Weir, M. W. (1966). Open-field behavior in mice: Evidence for a major gene effect mediated by the visual system. Science, 154(3756), 1577-1579.

Foynes, M. M., \& Riley, A. L. (2004). Lithium-chloride-induced conditioned taste aversions in the Lewis and Fischer 344 rat strains. Pharmacology Biochemistry and Behavior, 79(2), 303-308.

Garcia, J., Ervin, F. R., \& Koelling, R. A. (1966). Learning with prolonged delay of reinforcement. Psychonomic Science, 5(3), $121-122$.

Garcia, J., Kimeldorf, D. J., \& Koelling, R. A. (1955). Conditioned aversion to saccharin resulting from exposure to gamma radiation. Science, 122(3160), 157-158. https://org/10.1126/science.122. 3160.157

Gianfranceschi, L., Fiorentini, A., \& Maffei, L. (1999). Behavioural visual acuity of wild type and bcl 2 transgenic mouse. Vision research, 39(3), 569-574.
Horowitz, G. P., \& Whitney, G. (1975). Alcohol-induced conditioned aversion: Genotypic specificity in mice (Mus musculus). Journal of Comparative and Physiological Psychology, 89(4), 340.

Hunt, T., \& Amit, Z. (1987). Conditioned taste aversion induced by selfadministered drugs: Paradox revisited. Neuroscience \& Biobehavioral Reviews, 11(1), 107-130.

Kislal, S., \& Blizard, D. A. (2016). Conditioned context aversion learning in the laboratory mouse. Learning \& Behavior, 44(4), 309-319.

Mickley, G. A., Kenmuir, C. L., Yocom, A. M., Wellman, J. A., \& Biada, J. M. (2005). A role for prefrontal cortex in the extinction of a conditioned taste aversion. Brain Research, 1051(1), 176-182.

Nachman, M., \& Ashe, J. H. (1973). Learned taste aversions in rats as a function of dosage, concentration, and route of administration of LiCl. Physiology \& Behavior, 10(1), 73-78.

Nachman, M., Larue, C., \& Le Magnen, J. (1971). The role of olfactory and orosensory factors in the alcohol preference of inbred strains of mice. Physiology \& Behavior, 6(1), 53-59. https://org/10.1016/ 0031-9384(71)90014-X

Nowlis, G. H., Frank, M. E., \& Pfaffmann, C. (1980). Specificity of acquired aversions to taste qualities in hamsters and rats. Journal of Comparative and Physiological Psychology, 94(5), 932.

Parker, L. A. (2003). Taste avoidance and taste aversion: Evidence for two different processes. Animal Learning \& Behavior, 31(2), 165-172.

Prusky, G. T., Harker, K. T., Douglas, R. M., \& Whishaw, I. Q. (2002). Variation in visual acuity within pigmented, and between pigmented and albino rat strains. Behavioural Brain Research, 136(2), 339-348.

Revusky, S., \& Garcia, J. (1970). Learned associations over long delays. Psychology of Learning and Motivation, 4, 1-84.

Revusky, S., \& Parker, L. A. (1976). Aversions to unflavored water and cup drinking produced by delayed sickness. Journal of Experimental Psychology: Animal Behavior Processes, 2(4), 342.

Rodriguez, M., Lopez, M., Symonds, M., \& Hall, G. (2000). Lithiuminduced context aversion in rats as a model of anticipatory nausea in humans. Physiology \& Behavior, 71(5), 571-579.

Smith, J. C., \& Roll, D. L. (1967). Trace conditioning with X-rays as an aversive stimulus. Psychonomic Science, 9(1), 11-12.

Stockhorst, U., Enck, P., \& Klosterhalfen, S. (2007). Role of classical conditioning in learning gastrointestinal symptoms. World Journal of Gastroenterology: WJG, 13(25), 3430.

Stockhorst, U., Steingrueber, H. J., Enck, P., \& Klosterhalfen, S. (2006). Pavlovian conditioning of nausea and vomiting. Autonomic Neuroscience, 129(1), 50-57.

Welzl, H., D’Adamo, P., \& Lipp, H. P. (2001). Conditioned taste aversion as a learning and memory paradigm. Behavioural Brain Research, 125(1), 205-213.

Wong, A. A., \& Brown, R. E. (2006). Visual detection, pattern discrimination and visual acuity in 14 strains of mice. Genes, Brain and Behavior, 5(5), 389-403. 